Article

\title{
GM-Improved Antiaging Effect of Acrylonitrile Butadiene Styrene in Different Thermal Environments
}

\author{
Yuchao Wang ${ }^{1,2}$, Ming Chen ${ }^{1}$, Miaoyu Lan ${ }^{1}, \mathrm{Zhi} \mathrm{Li}^{1}$, Shulai $\mathrm{Lu}{ }^{1, *}$ and Guangfeng $\mathrm{Wu}^{2, *}$ \\ 1 ABS Technology Center of PetroChina, Jilin 132021, China; jh_wangyuc@petrochina.com.cn (Y.W.); \\ jh_chming@petrochina.com.cn (M.C.); jh_lanmy@petrochina.com.cn (M.L.); \\ jh_lzhi@petrochina.com.cn (Z.L.) \\ 2 School of Chemical Engineering, Changchun University of Technology, Changchun 130012, China \\ * Correspondence: jh_lus1@petrochina.com.cn (S.L.); gfwu20@163.com (G.W.)
}

Received: 16 November 2019; Accepted: 20 December 2019; Published: 28 December 2019

\begin{abstract}
A stabilizer called 2-tert-butyl-6-(3-tert-butyl-2-hydroxy-5-methylbenzyl)-4-methylphenyl acrylate (GM) was mixed in acrylonitrile butadiene styrene (ABS) with the same amount of 9-bis(octadecyloxy)-2,4,8,10-tetraoxa-3,9-diphosphaspiro[5.5]undecane (DSPDP), octadecyl-3-(3,5-di-tert-butyl-4-hydroxyphenyl) propionate (Irganox 1076) and tris(3,5-di-tert-butyl-4-hydroxybenzyl) isocyanurate (Irganox 3114) to investigate the influence of additives on the antiaging effect of ABS in oven aging or repeated extrusion aging. It was found that the ABS doped with the GM stabilizer showed a better yellowing resistance and thermal stability than the ABS doped with other antioxidants. Owing to the fact that the stabilizer can act on the free radicals before it has been peroxidized, it could trap the free radicals as a consequence of directly blocking the oxidation process of the active species, thus solving the problem of oxidative degradation of the materials from the source. This work provides guidance for improving thermal stability of ABS, indicating a promising potential for industrial application.
\end{abstract}

Keywords: polymer degradation; acrylonitrile butadiene styrene; convection oven; extrusion; recycling; mechanical properties

\section{Introduction}

Acrylonitrile butadiene styrene (ABS) resins have attracted considerable attention due to their superior mechanical properties [1], heat resistance [2], chemical resistance [3], recyclability [4-6] and ease of processing $[7,8]$, and are widely used in telecommunications, automotive industry, consumer markets and business machines [9,10]. However, ABS is easily excited by the heat [11,12], light [13-15], oxygen $[16,17]$ and other conditions during its processing [18,19], leading to aging degradations of the material. Because the presence of unstable carbon-carbon double bonds in the butadiene microstructure generates macromolecular-active radicals during processing, thermal degradation is promoted and results in a rapid yellowing and brittleness of ABS [20,21].

To solve this problem, most of previous reports employed doping strategy to prepare highly aging-resistant ABS resins. Some people chose traditional additives to improve heat resistance. For example, Fiorio's group found that the addition of primary antioxidants in ABS increases the thermal-oxidative stability, whereas the secondary antioxidants only increase the oxidation peak temperature [22]. Others have chosen new types of additives. Ong's group showed that pretreatments on filled oil palm fiber can lower the onset thermal degradation temperature of acrylonitrile butadiene styrene composites in differential thermogravimetric analysis [23]. Teh's group successfully improved 
the thermal stability of the ABS resin by adding carbon black (CB) to the ABS [24]. Yan's group enhanced the electrical conductivity and thermal conductivity of the ABS via the addition of reduced graphene oxide (rGO) in the ABS resin, because it can tightly wrap the rGO sheet on the surface of ABS microspheres [25]. In addition, Allen's group used other stabilizers to conduct a comprehensive study of K-resin by both thermal-aging degradation and photo-aging degradation [26]. However, the doping strategy also brings about changes in the color-phase morphology or other properties thereof. This dilemma makes it difficult to explore the improved thermal stability for the ABS resin [27].

Here, we successfully obtained high thermal stability ABS through a doping strategy without affecting the properties of ABS itself. A systematic study was carried out to investigate effects of 2-tert-butyl-6-(3-tert-butyl-2-hydroxy-5-methylbenzyl)-4-methylphenyl acrylate (GM), 9-bis(octadecyloxy)-2,4,8,10-tetraoxa-3,9-diphosphaspiro[5.5]undecane (DSPDP), octadecyl-3-(3,5-di-tert-butyl-4-hydroxyphenyl) propionate (Irganox 1076) and tris(3,5-ditert-butyl-4-hydroxybenzyl) isocyanurate (Irganox 3114) antioxidants on the thermal aging of ABS in two different thermal environments, a $100{ }^{\circ} \mathrm{C}$ convection oven and a $240{ }^{\circ} \mathrm{C}$ extruder simulating the extreme environment. It was found that the ABS doped with the GM stabilizer showed better yellowing resistance and thermal stability than the ABS doped with other antioxidants. Owing to the fact that the stabilizer can act on the free radicals before it has been peroxidized, it could trap the free radicals as a consequence of directly blocking the oxidation process of the active species, thus solving the problem of oxidative degradation of the materials from the source. Hence, the GM antioxidant can greatly improve thermal stability of the ABS in the convection oven or the extruder. This work provides guidance for improving thermal stability of ABS, indicating promising potential for industrial application.

\section{Materials and Methods}

\subsection{Materials}

The materials used in this study were as follows: ABS-grafted powder PW-151 (KunLun, Jilin, China, obtained by emulsion polymerization), SAN resin 2437 (KunLun, Jilin, China), acrylic acid (Sigma Aldrich, Shanghai, China), phosphoryl trichloride (Sigma Aldrich, Shanghai, China), triethylamine (TEAE), 2,2'-methylenebis(6-tert-butyl-4-methylphenol) (Antioxidant 2246, Sigma Aldrich, Shanghai, China), GM (laboratory homemade), DSPDP (Cytec, Jilin, China, phosphite secondary antioxidant), Irganox 1076 (BASF, Shanghai, China, phenolic primary antioxidant) and Irganox 3114 (BASF, Shanghai, China, antioxidant-stabilizer).

\subsection{Synthesis of Stabilizer GM}

Firstly, $120 \mathrm{~g}$ of Antioxidant 2246, $20 \mathrm{~g}$ of acrylic acid, $2.0 \mathrm{~g}$ of triethylamine and an appropriate amount of the organic solvent were sequentially added to a $1000 \mathrm{~mL}$ four-necked flask. After heating in an oil bath under stirring, the temperature was raised to about $110{ }^{\circ} \mathrm{C}$ and $30 \mathrm{~g}$ of phosphoryl trichloride were added dropwise; the dropwise addition was completed in $45 \mathrm{~min}$. The dropped raw material reacted to release a small amount of hydrogen chloride gas which was absorbed by the hydrogen chloride absorber. The temperature was maintained for $3 \mathrm{~h}$ before the reaction was completed. Thereafter, the organic solvent recrystallization method was used to purify the crude reaction product. Finally, a yellowish crystalline product was obtained which is referred to as Stabilizer GM. We use the synthetic method in the article by Yachigo's group to obtain the uniform-quality stabilizer GM from the raw materials, so as to obtain reliable and repeatable experimental results [28].

\subsection{Sample Preparation}

The ABS grafted powder and the SAN resin were mixed at a mass ratio of 25:75, and four equal parts of the GM, DSPDP, Irganox 1076 and Irganox 3114 were added in in the mixture, then sheared and granulated the mixture by a twin-screw extruder at $240{ }^{\circ} \mathrm{C}$. The granulated ABS-material was subjected 
to a series of eight cycles of oven aging at $100{ }^{\circ} \mathrm{C}$ for $72 \mathrm{~h}$ per cycle, or five cycles of anaerobic repeated extrusion at $240{ }^{\circ} \mathrm{C}$. We chose the temperature at 100 and $240{ }^{\circ} \mathrm{C}$ was because these temperatures presented greater challenge for the additives to maintain the same performance of the materials. In addition, it was more intuitively to compare the differences of each additives in the protective ability [6,29-32].

\subsection{Analysis}

\subsubsection{Fourier Transform Infrared Spectroscopy (FTIR)}

Fourier transform infrared spectroscopy (FTIR, IR Prestige-21, Shimadz, Kyoto, Japan) was used to evaluate the four additives and changes in ABS samples through accelerated degradation. All samples were studied in attenuated total reflectance (ATR) mode from 4000 to $600 \mathrm{~cm}^{-1}$. The spectra of ABS samples form an absorbance peak of carbonyl at $1720 \mathrm{~cm}^{-1}$ during degradation, which was compared to the absorbance peak of acrylonitrile at $2237 \mathrm{~cm}^{-1}$. The integral ratio between the absorbance peak at $1720 \mathrm{~cm}^{-1}$ (carbonyl) and that at $2237 \mathrm{~cm}^{-1}$ (acrylonitrile) was defined as the carbonyl index, the equation is as follows [33-35]:

$$
\text { Carbonyl index }=\frac{\text { Transmittance at } 1720 \mathrm{~cm}^{-1}}{\text { Transmittance at } 2237 \mathrm{~cm}^{-1}} .
$$

\subsubsection{Thermogravimetric Analysis (TGA)}

All raw materials were characterized simultaneously by thermogravimetric analysis (STA 449 F5, Netzsch, Selb, Germany). Samples (for the results, see Figure S1) of $10 \pm 2 \mathrm{mg}$ were heated from 25 to $600{ }^{\circ} \mathrm{C}$ at a heating rate of $10{ }^{\circ} \mathrm{C} \mathrm{min}-1$ in a $\mathrm{Pt}-\mathrm{Rh}$ pan [36]. The shielding gas was high-purity nitrogen and the flow rate set to $20 \mathrm{~mL} \cdot \mathrm{min}^{-1}$. The purge gas was air and the flow rate set to $20 \mathrm{~mL} \cdot \mathrm{min}^{-1}$.

\subsubsection{Color Measurements}

The color properties of the samples were investigated with a spectrophotometer (UltraScan PRO, Hunterlab, Reston, VA, USA) using a Artificial Daylight 6500K (D65) light source and $10^{\circ}$ viewing angle. All color measurements were obtained from the compression molded films.

The color difference $(\Delta E)$ between the two sets of injection samples was tested. One was that the temperature of the cutting section of the plastic cylinder was $220^{\circ} \mathrm{C}$ and the residence time of the cylinder $40 \mathrm{~s}$. The other was that the temperature of the cutting section of the plastic cylinder was $250{ }^{\circ} \mathrm{C}$ and the residence time $180 \mathrm{~s}$. The difference between the heat resistance of the ABS resin additives was characterized by testing the color difference values of ABS samples under these two conditions.

The results show three colorimetric coordinates: luminosity $(L)$, red/green component $(a)$ and blue/yellow component $(b)$. The total color difference $(\Delta E)$ between the samples caused by temperature or time change was calculated using Equations (2) and (3) [35]:

$$
\begin{aligned}
& \Delta E=\sqrt{\Delta L^{2}+\Delta a^{2}+\Delta b^{2}}
\end{aligned}
$$

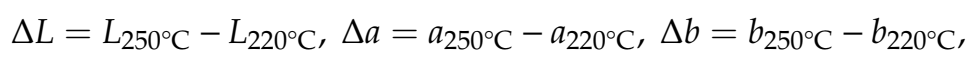

where $\Delta L$ is the difference of the injection-molded-samples between $250{ }^{\circ} \mathrm{C}$ and $220{ }^{\circ} \mathrm{C}, \Delta a$ is red/green component difference between the samples under the two different temperatures and $\Delta b$ is the difference of the blue/yellow component.

The yellowing index (YI) was obtained by the International Commission on illumination (CIE) tristimulus values $X, Y$ and $Z$ according to the CIELAB color system [37]. The YI was determined according to Equation (4) [22]:

$$
\mathrm{YI}=\frac{100 \times(1.3013 X-1.1498 Z)}{Y}
$$




\subsubsection{Mechanical Testing}

Notched-impact strength and melt-index rate (MFR) were measured according to ASTM-D256 and ASTM-D1238 standards, respectively.

\section{Results}

\subsection{Additive Selection}

To systematically study and understand the influence of additives on the antiaging effect of ABS, the additives GM, DSPDP, Irganox 1076 and Irganox 3114 were selected to dope the ABS. The molecular structure of the additives is shown in Figure 1a. Figure 1b shows the Fourier transform infrared spectroscopy of the additives. In our experiment, we synthesized the stabilizer GM. As shown in Figure 1b, 804 and $856 \mathrm{~cm}^{-1}$ are the bending vibration peaks of the benzene ring; the stretching vibration peak of the benzene appears at $1599 \mathrm{~cm}^{-1}$, which proves that the synthesized GM material does contain the benzene ring group. The -OH bending vibration peak appears at $1358 \mathrm{~cm}^{-1}$, indicating that the synthesized GM material contains the phenolic hydroxyl functional group. In addition, the 1161,1633 and $1729 \mathrm{~cm}^{-1}$ peaks are $\mathrm{C}-\mathrm{O}, \mathrm{C}=\mathrm{C}$ and $\mathrm{C}=\mathrm{O}$ stretching vibration peaks, respectively, indicating that the microscopic benzene ring structure of the sample is attached with an acrylic group. In summary, the prepared material is a desired GM product containing a bisphenol acryloyl group. Figure $1 \mathrm{~b}$ also shows the Fourier transform infrared spectroscopy of DSPDP, Irganox 1076 and Irganox 3114 , three other additives, showing $\mathrm{POC}, \mathrm{Ar}-\mathrm{OH}$ and $=\mathrm{CH}$, three characteristic functional groups appearing at 1032, 3638 and $852 \mathrm{~cm}^{-1}$.
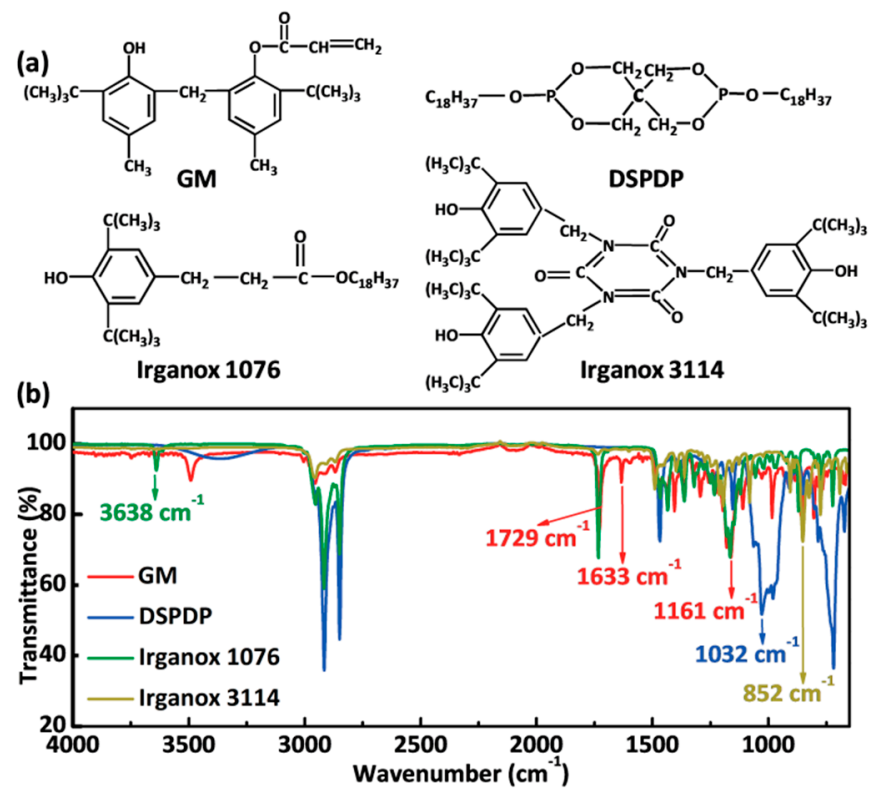

Figure 1. (a) Molecular structure of different additives; 2-tert-butyl-6-(3-tert-butyl-2-hydroxy-5methylbenzyl)-4-methylphenyl acrylate (GM), 9-bis(octadecyloxy)-2,4,8,10-tetraoxa-3,9diphosphaspiro[5.5]undecane (DSPDP), octadecyl-3-(3,5-di-tert-butyl-4-hydroxyphenyl) propionate (Irganox 1076) and tris(3,5-di-tert-butyl-4-hydroxybenzyl) isocyanurate (Irganox 3114). (b) Fourier transform infrared spectroscopy of the additives.

The four kinds of additives we selected play different roles in the thermal-oxidation process. The GM stabilization mechanism is confirmed to be a unique bifunctional mechanism, which consists of polymer radical trapping by the acrylate group, followed by rapid hydrogen transfer from intramolecular hydrogen-bonded phenolic hydroxyl groups to form stable phenoxyl radicals. Therefore, the problem of oxidative degradation of materials is solved from the source of the thermal-oxidation process (for the schematic, see Figure S2). DSPDP acts as a hydroperoxide scavenger that rapidly 
decomposes macromolecular hydrogen peroxide, stopping the thermal-oxidation process and thus preventing continued aging. Irganox 1076 and Irganox 3114 act as radical scavengers that react with macromolecular peroxidative free radicals to inhibit the partial thermal-oxidation process and hence slows aging. It can be confirmed that GM has a unique heat-resistant effect compared with traditional primary and secondary antioxidants.

\subsection{Carbonyl Index}

To explore the influence of additives on the antiaging effect of ABS, we calculated the carbonyl index (CI) of ABS with different additives. The carbonyl index is defined as the integral ratio because the absorbance peaks of acryloacrylonitrile are usually unchanged during degradation progress. The oxidation of the polybutadiene rubber phase of ABS material would form carbonyl groups in the degradation, so that the degradation of the material can be evaluated from the change of the carbonyl absorption peak. The Fourier transform infrared spectroscopy of ABS with different additives after eight cycles in the oven aging at $100^{\circ} \mathrm{C}$ for $72 \mathrm{~h}$ is shown in Figure 2a. Figure $2 \mathrm{~b}$ shows the dependence of carbonyl index for ABS with different additives on the number of cycles in the oven aging at $100^{\circ} \mathrm{C}$ for $72 \mathrm{~h}$. It can be clearly observed that the carbonyl index value of ABS with the GM is the lowest, only 0.68, which is much smaller than that of ABS with DSPDP, Irganox 1076 and Irganox 3114. This result indicated that the ABS with the GM exhibited the least aging, and the additive of GM successfully improved the antiaging effect of ABS. It is confirmed that the effect of the GM additive, which solves the problem of oxidative degradation of materials from the source of the thermal-oxidation process, and is stronger than that of the additive of DSPDP (hydroperoxide scavenger), Irganox 1076 or Irganox 3114 (radical scavengers).
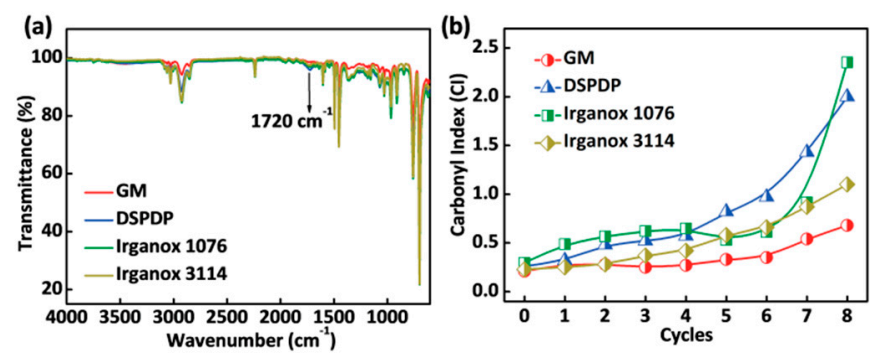

Figure 2. (a) Fourier transform infrared spectroscopy (FTIR) of acrylonitrile butadiene styrene (ABS) with different additives after eight cycles at $100^{\circ} \mathrm{C}$. (b) Carbonyl index versus aging cycles for ABS with different additives at $100^{\circ} \mathrm{C}$.

\subsection{Thermal Properties}

To further explore the influence of additives on the antiaging effect of ABS, we evaluated the temperature of ABS with different additives under different weight loss in the two different thermal environments. Figure 3 shows the temperature from thermogravimetric analysis (TGA) of different weight loss for ABS with different additives after eight cycles in the oven aging at $100{ }^{\circ} \mathrm{C}$ for $72 \mathrm{~h}$. The initial $1 \%$ decomposition temperature $\left(T_{1 \%}\right)$ of ABS with different additives in the convection oven is shown in Figure 3a. It can be observed that the initial decomposition temperatures of ABS with GM, DSPDP, Irganox 1076 and Irganox 3114 all show a tendency to decrease first and then increase as the number of aging cycles increased. The temperature drop is due to the partial aging of the added chemicals in the aerobic environment during the first three cycles. When the sample was placed in the thermogravimetric analyzer with similar high temperature, the added group was oxidized prior to the ABS sample, which lowered the overall initial $T_{1 \%}$ decomposition temperature. The $T_{1 \%}$ rose after $3-5$ cycles because the addition of antioxidant was almost oxidized and could no longer affect the decomposition temperature of the ABS resin. Moreover, the $1 \%$ mass decomposition temperature of ABS with GM and DSPDP is almost higher than that of ABS with Irganox 1076 and Irganox 3114. This phenomenon also appears for $T_{3 \%}$ and $T_{5 \%}$, shown in Figure $3 \mathrm{~b}, \mathrm{c}$, which indicates that the acrylate 
functional group, unique to GM, and the phosphite structure contained in DSPDP play an important role in resistance to the thermal-oxidative degradation of polymers.
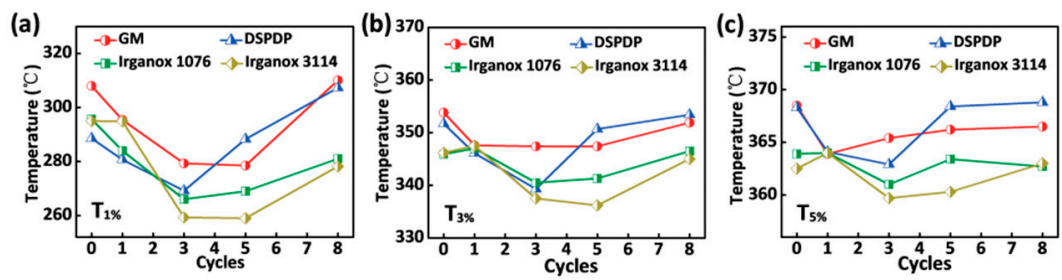

Figure 3. (a) Temperature of $1 \%$ weight loss for ABS with different additives; (b) temperature of $3 \%$ weight loss for ABS with different additives; and (c) temperature of $5 \%$ weight loss for ABS with different additives.

In addition, dependence of the initial temperature on the weight loss for ABS with different additives after extrusion steps is shown in Figure 4. During the extrusion process, it is easy to produce a high temperature and anoxic environment when the material is filled between the screw and the barrel. Figure $4 \mathrm{a}$ shows the initial degradation temperature of $\mathrm{ABS}$ with different additives after one extrusion process. It can be seen that the thermal decomposition temperature of ABS with GM, DSPDP, Irganox 1076 and Irganox 3114 are approximately the same, and as the percentage of weight loss increased, the trend of thermal decomposition temperature remained consistent. As the number of cycles increased to three (Figure $4 \mathrm{~b}$ ), the thermal decomposition temperature of ABS with GM was higher than that of ABS with other additives. This is because the acrylate structure of bisphenol monoacrylate can quickly capture macromolecule free radicals at the initial stage (Equation (5)), thus preventing macromolecules from self-crosslinking (Equation (6)). The special bisphenol monoacrylate generates a relatively stable radical ending reaction. As shown in Figure $4 \mathrm{c}, \mathrm{d}$, the stabilizer GM can similarly increase the heat resistance of the ABS sample after 5-6 extrusions.

$$
\begin{gathered}
\mathrm{R} \bullet+\ln \mathrm{H} \rightarrow \mathrm{RH}+\ln \bullet \\
2 \mathrm{R} \bullet \rightarrow \mathrm{R}-\mathrm{R}
\end{gathered}
$$

where $\mathrm{R} \bullet$ represents macromolecule free radicals, RH represents stable macromolecule.
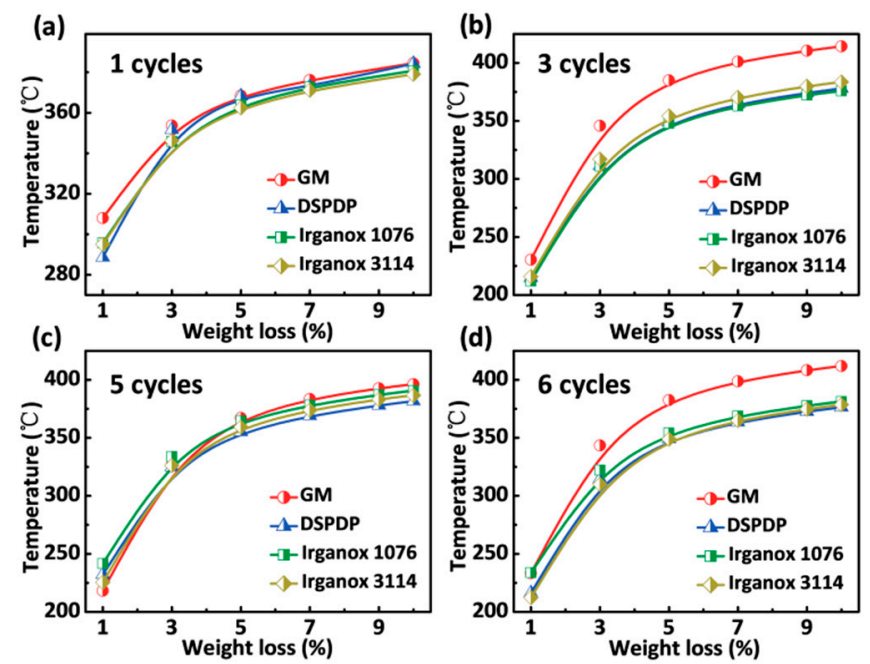

Figure 4. Dependence of the initial temperature on the weight loss for ABS with different additives after different extrusion times: (a) the first extrusion; (b) the third extrusion; (c) the fifth extrusion; and (d) the sixth extrusion. 


\subsection{Optical and Mechanical Properties}

Last but not least, we also explored the influence of additives on the optical and mechanical properties of ABS in two different thermal environments. Figures 5 and 6 show the optical and mechanical properties of ABS with different additives after aging within the convection oven and the extruder. The additive of GM not only improved the thermal stability of ABS, but it also had a good color promotion in the two different thermal environments. As shown in Figures $5 \mathrm{a}$ and $6 \mathrm{a}$, it can be observed that the ABS with different additives yellowed after oven aging or repeated extrusion aging. The yellow index of ABS with different additives increased as well as the color difference given in Figures $5 b$ and $6 b$.

According to the Equation (7), and further combining the yellow index with the color difference index, the phosphite group contained in the ABS with DSPDP reacts faster to decompose hydroperoxide when compared to other samples:

$$
\mathrm{ROOH}+2\left(\mathrm{R}^{\prime} \mathrm{O}\right) 3 \mathrm{POH} \rightarrow 2\left(\mathrm{R}^{\prime} \mathrm{O}\right)_{3} \mathrm{P}=\mathrm{O}+\mathrm{ROH}+\mathrm{H}_{2} \mathrm{O}
$$

where $\mathrm{R}$ repersents the alkyl group in macromolecular, $\mathrm{R}^{\prime}$ repersents the alkyl group in DSPDP.

The increase of color stability of ABS with Irganox 1076 indicates that the hindered phenolic antioxidant easily forms anthraquinone after absorbing the peroxy radical, causing the material to turn yellow.

Furthermore, a cantilever-beam impact tester was used to analyze the notched impact strength (IZOD) of ABS with different additives after aging by the convection oven or the extruder. In addition, the molecular mobility of ABS with different additives was analyzed using a melt-flow tester. The notched impact strength of ABS with different additives is shown in Figures $5 c$ and $6 c$, and the melt flow rate (MFR) is shown in Figures $5 d$ and $6 \mathrm{~d}$. As shown in Figure $5 c, d$, the impact toughness and molecular fluidity of ABS with different additives did not significantly attenuate when compared to pure ABS (for the results, see Figure S3) after aging by the convection oven, indicating that the resin itself had no serious cross-linking phenomenon, and the addition of the antioxidant had no effect on the impact strength and melt flow rate. Figure $6 \mathrm{c}$,d demonstrate that the ABS undergoes considerable cross-linking, which shows an evident decrease in melt flow rate. The ABS sample with GM increased its impact strength and melt flow rate of ABS, indicating that the bifunctional group in GM can prevent the macromolecular radical cross-linking curing caused by less oxygen in repeated extrusion.
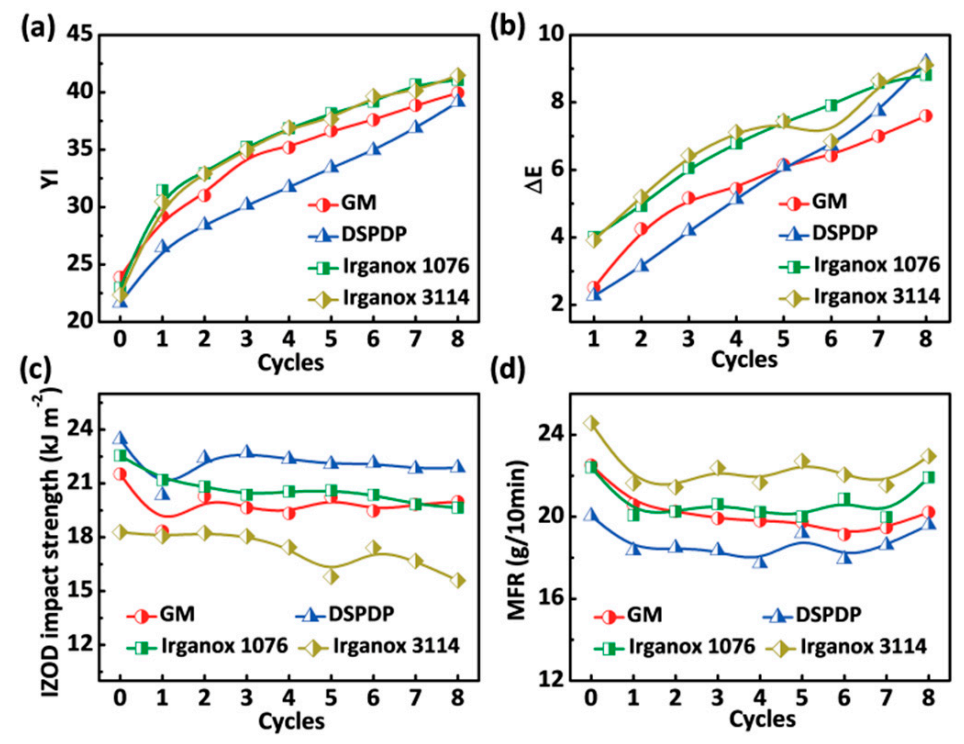

Figure 5. Optical and mechanical properties versus aging cycles for ABS: (a) yellow index (YI); (b) color difference value $(\Delta E) ;(\mathbf{c})$ notched impact strength; and (d) melt flow rate (MFR). 
(a)

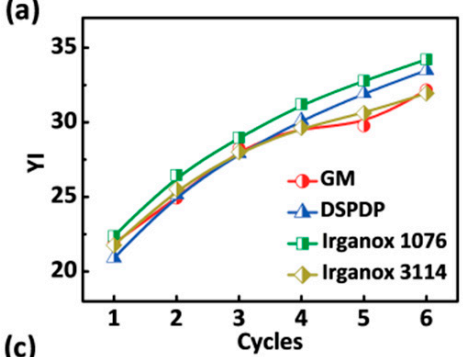

(c)

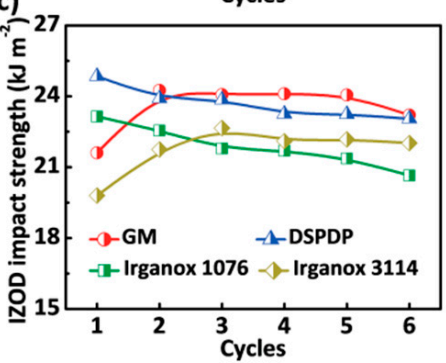

(b)
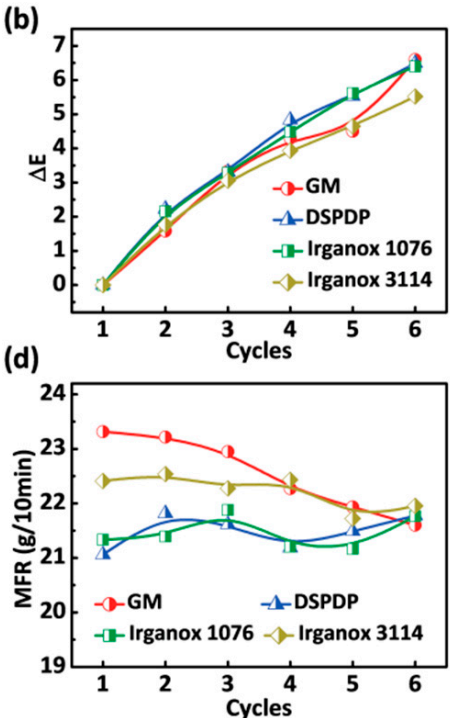

Figure 6. Optical and mechanical properties versus repeated extrusion for ABS: (a) yellow index (YI); (b) color difference value $(\Delta E)$; (c) notched impact strength; and (d) melt flow rate (MFR).

\section{Conclusions}

In summary, we successfully obtained high thermal stability and a better yellowing-resistant ABS with the GM additive in the convection oven or the extruder. In the oxygen convection oven environment, the polybutadiene double bond of the ABS was attacked by the active free radical to form a carbonyl group. It can be clearly observed from the FTIR that the carbonyl index value of ABS with the GM is the lowest, which is much smaller than that of ABS with DSPDP, Irganox 1076 and Irganox 3114. As the number of aging cycles increased, the thermal decomposition temperature (TGA) of ABS with GM was higher than that of ABS with other additives. These results indicated that the difunctional structure of GM could reduce the formation of carbonyl group by the reaction with free radicals prior to aging degradation. It also proved that the acrylate structure of bisphenol monoacrylate can rapidly capture macromolecular free radicals in the initial stage, generate relatively stable free radicals and terminate the reaction. In the extrusion environment with less oxygen, the lower yellow index and smaller chromatic aberration demonstrated better color retention of ABS sample with GM. The higher melt flow rate of ABS sample with GM also indicated its excellent ability to capture macromolecular radicals. It could effectively inhibit the cross-linking of polymers, slow the aging of materials and improve the heat-aging resistance of ABS.

Supplementary Materials: The following are available online at http://www.mdpi.com/2073-4360/12/1/46/s1, Figure S1: Thermogravimetric analysis (TGA) results for ABS with different additives after different extrusion times: (a) the first extrusion, (b) the third extrusion, (c) the fifth extrusion, (d) the sixth extrusion; Figure S2: General scheme of thermal-oxidative degradation of ABS resin and its inhibition mechanism by GM, DSPDP, Irganox 1076, and Irganox 3114; Figure S3: (a) Notched impact strength of pure ABS aged by thermal oven, (b) Melt flow rate of pure ABS aged by thermal oven.

Author Contributions: Conceptualization, S.L. and Y.W.; Methodology, Y.W.; Validation, Y.W.; Formal Analysis, G.W. and Y.W.; Investigation, Y.W.; Resources, S.L.; Writing-Original Draft Preparation, Y.W.; Writing-Review and Editing, Y.W., M.C., M.L. and Z.L.; Visualization, Y.W., M.C., M.L. and Z.L.; Supervision, S.L.; Project Administration, S.L. All authors have read and agreed to the published version of the manuscript.

Funding: This research received no external funding.

Conflicts of Interest: The authors declare no conflict of interest. 


\section{References}

1. Lin, J.; Li, J.; Wang, J.; Guan, Y.; Wang, G.; Chen, L. Effects of thermoplastic elastomer on the morphology and mechanical properties of glass fiber-reinforced polycarbonate/acrylonitrile-butadiene-styrene. Polym. Eng. Sci. 2019, 59, E144-E151. [CrossRef]

2. Zhang, A.; Mu, B.; Wang, X.; Wang, A. Microwave hydrothermal assisted preparation of $\mathrm{CoAl}_{2} \mathrm{O}_{4} / \mathrm{kaolin}$ hybrid pigments for reinforcement coloring and mechanical property of acrylonitrile butadiene styrene. Appl. Clay Sci. 2019, 175, 67-75. [CrossRef]

3. Ahmed, J.K. Studying yhe effect of nano silver on some properties of acrylonitrile butadiene styrene copolymer for medical device. Int. J. Eng. Technol. 2019, 8, 208-213.

4. Kuram, E. Hybridization effect of talc/glass fiber as a filler in polycarbonate/acrylonitrile-butadiene-styrene composites. Compos. Part B 2019, 173, 106954. [CrossRef]

5. Rahimi, M.; Esfahanian, M.; Moradi, M. Effect of reprocessing on shrinkage and mechanical properties of ABS and investigating the proper blend of virgin and recycled ABS in injection molding. J. Mater. Process. Technol. 2014, 214, 2359-2365. [CrossRef]

6. Scaffaro, R.; Botta, L.; Benedetto, G.D. Physical properties of virgin-recycled ABS blends: Effect of post-consumer content and of reprocessing cycles. Eur. Polym. J. 2012, 48, 637-648. [CrossRef]

7. Kim, S.H.; Choi, K.; Choi, H.R.; Kim, T.; Suhr, J.; Kim, K.J.; Choi, H.J.; Nam, J.D. Non-einstein viscosity phenomenon of acrylonitrile-butadiene-styrene composites containing lignin-polycaprolactone particulates highly dispersed by high-shear stress. ACS Omega 2019, 4, 10036-10043. [CrossRef]

8. Peterson, A.M. Review of acrylonitrile butadiene styrene in fused filament fabrication: A plastics engineering-focused perspective. Addit. Manuf. 2019, 27, 363-371. [CrossRef]

9. Lu, Y.; Yang, M.; Liu, J. Morphology and properties of thin-walled microcellular polycarbonate/acrylonitrile-butadiene-styrene blend foam. J. Cell. Plast. 2019, 55, 421-432. [CrossRef]

10. Huang, B.; Meng, S.; He, H.; Jia, Y.; Xu, Y.; Huang, H. Study of processing parameters in fused deposition modeling based on mechanical properties of acrylonitrile-butadiene-styrene filament. Polym. Eng. Sci. 2019, 59, 120-128. [CrossRef]

11. Rasero, M.Á.P. Metodologia Para el Calculo Dela Viscosidad Empleando Como Caso Practico el Reprocesado de ABS. 3c Tecnología 2012, 1, 33-47.

12. Tiganis, B.E. Thermal degradation of acrylonitrile-butadiene-styrene (ABS) blends. Polym. Degrad. Stab. 2002, 76, 425-434. [CrossRef]

13. Belavadi Venkataramaiah, S.; Shridhar, T.N.; Mannikar, A.V.; Mohan Krishna, S.A. Comprehensive investigation of acrylonitrile-butadiene-styrene (ABS) polymer for weathering with the combination of different blends of UV stabilizers, HALS and antioxidant. SAE Tech. Paper Ser. 2019, 26, 0619.

14. Saviello, D.; Pouyet, E.; Toniolo, L.; Cotte, M.; Nevin, A. Synchrotron-based FTIR microspectroscopy for the mapping of photo-oxidation and additives in acrylonitrile-butadiene-styrene model samples and historical objects. Anal. Chim. Acta 2014, 843, 59-72. [CrossRef]

15. Davis, P. The effect of photo-oxidative degradation on fracture in ABS pipe resins. Polym. Degrad. Stab. 2004, 84, 233-242. [CrossRef]

16. Cristea, E.; Sturza, R.; Auregi, P.; Niculaua, J.M.; Ghendov-Mosanu, A.; Patras, A. Influence of pH and ionic strength on the color parameters and antioxidant properties of an ethanolic red grape marc extract. J. Food Biochem. 2019, 43, e12788. [CrossRef]

17. Wang, J.; Cai, X.-F. Kinetics study of thermal oxidative degradation of ABS containing flame retardant components. J. Therm. Anal. Calorim. 2011, 107, 725-732. [CrossRef]

18. Conway, K.M.; Pataky, G.J. Crazing in additively manufactured acrylonitrile butadiene styrene. Eng. Fract. Mech. 2019, 211, 114-124. [CrossRef]

19. Guessasma, S.; Belhabib, S.; Nouri, H. Microstructure, Thermal and mechanical behavior of 3D printed acrylonitrile styrene acrylate. Macromol. Mater. Eng. 2019, 304, 1800793. [CrossRef]

20. Blom, H.; Yeh, R.; Wojnarowski, R.; Ling, M. Retracted: Detection of degradation of ABS materials via DSC. Thermochim. Acta 2006, 442, 64-66. [CrossRef]

21. Salari, D. Study on the recycling of ABS resins: Simulation of reprocessing and thermo-oxidation. Iran. Polym. J. 2008, 17, 599-610. 
22. Fiorio, R.; D'Hooge, D.R.; Ragaert, K.; Cardon, L. A statistical analysis on the effect of antioxidants on the thermal-oxidative stability of commercial mass- and emulsion-polymerized ABS. Polymers 2018, 11, 25. [CrossRef] [PubMed]

23. Ong, T.K.; Tshai, K.Y.; Khiew, P.S.; Yap, E.H. Thermal and mechanical properties of chemically treated oil palm fiber filled acrylonitrile butadiene styrene composites. Mater. Werkst. 2019, 50, 240-247. [CrossRef]

24. Chan, M.Y.; Teh, P.L.; Yeoh, C.K. Effect of blend ratio on the properties of polystyrene/acrylonitrile butadiene styrene/carbon black (PS/ABS/CB) conductive materials. J. Eng. Sci. 2019, 15, 63-75. [CrossRef]

25. Gao, A.; Zhao, F.; Wang, F.; Zhang, G.; Zhao, S.; Cui, J.; Yan, Y. Highly conductive and light-weight acrylonitrile-butadiene-styrene copolymer/reduced graphene nanocomposites with segregated conductive structure. Compos. Part A 2019, 122, 1-7. [CrossRef]

26. Allen, N.S.; Barcelona, A.; Edge, M.; Wilkinson, A.; Merchan, C.G.; Quiteria, V.R.S. Aspects of the thermal and photostabilisation of high styrene-butadiene copolymer (SBC). Polym. Degrad. Stab. 2006, 91, 1395-1416. [CrossRef]

27. Triantou, M.I.; Chatzigiannakis, E.M.; Tarantili, P.A. Evaluation of thermal degradation mechanisms and their effect on the gross calorific value of ABS/PC/organoclay nanocomposites. J. Therm. Anal. Calorim. 2014, 119, 337-347. [CrossRef]

28. Yachigo, S.; Sasaki, M.; Takahashi, Y.; Kojima, F.; Takada, T.; Okita, T. Studies on polymer stabilisers: Part I-A novel thermal stabiliser for butadiene polymers. Polym. Degrad. Stab. 1988, 22, 63-77. [CrossRef]

29. Shimada, J.; Kabuki, K. The mechanism of oxidative degradation of ABS resin. Part I. The mechanism of thermooxidative degradation. J. Appl. Polym. Sci. 1968, 12, 655-669. [CrossRef]

30. Wyzgoski, M.G. Effects of oven aging on ABS, poly (acrylonitrile-butadiene-styrene). Polym. Eng. Sci. 1976, 16, 265-269. [CrossRef]

31. Boldizar, A.; Möller, K. Degradation of ABS during repeated processing and accelerated ageing. Polym. Degrad. Stab. 2003, 81, 359-366. [CrossRef]

32. Rosik, L.; Kovářová, J.; Pospíšil, J. Lifetime prediction of ABS polymers based on thermoanalytical data. J. Therm. Anal. 1996, 46, 465-470. [CrossRef]

33. Bai, X.; Isaac, D.H.; Smith, K. Reprocessing acrylonitrile-butadiene-styrene plastics: Structure-property relationships. Polym. Eng. Sci. 2007, 47, 120-130. [CrossRef]

34. Hassinen, J. Deterioration of polyethylene pipes exposed to chlorinated water. Polym. Degrad. Stab. 2004, 84, 261-267. [CrossRef]

35. Santos, R.M.; Botelho, G.L.; Machado, A.V. Artificial and natural weathering of ABS. J. Appl. Polym. Sci. 2010, 116, 2005-2014. [CrossRef]

36. Suzuki, M.; Wilkie, C.A. The thermal degradation of acrylonitrile-butadiene-styrene terpolymei as studied by TGA/FTIR. Polym. Degrad. Stab. 1995, 47, 217-221. [CrossRef]

37. Griesser, R. Assessment of whiteness and tint of fluorescent substrates with good interinstrument correlation. Color Res. Appl. 1994, 19, 446-460. [CrossRef]

(C) 2019 by the authors. Licensee MDPI, Basel, Switzerland. This article is an open access article distributed under the terms and conditions of the Creative Commons Attribution (CC BY) license (http://creativecommons.org/licenses/by/4.0/). 